ICACCG2020 30-31 July, 2020, Ansal University, Gurgaon, India

International Journal of Technical Research \& Science (Special Issue) ISSN No.:2454-2024 (online)

\title{
PROPOSED METHOD FOR CAR THEFT PREVENTION TECHNIQUES
}

\author{
Eva Thakran ${ }^{1}$, Shrestha Bhattacharya ${ }^{2}$, Seema Verma ${ }^{3}$ \\ E-Mail Id: ${ }^{1}$ evathakran1999@gmail.com, ${ }^{2}$ shresthabhattacharya635@gmail.com, \\ ${ }^{3}$ seemaverma.fet@mriu.edu.in \\ Manav Rachna International Institute of Research and Studies, Faridabad, Haryana, India
}

\begin{abstract}
This paper aims to provide a tactical approach to prevent car theft and recovery methods to recover the stolen car. In this work, different car theft prevention techniques are studied and survey has been done on various customers to have a better picture of their requirement. A new car theft prevention technique has been proposed based on the survey done. The basis of the proposed method is for tracking the car alarm system which has noise, light and button sensors which are used to monitor the different parts of the car.
\end{abstract}

Keywords: Car theft prevention techniques, GPS System, RFID technology, sensors.

\section{INTRODUCTION}

Car theft is a criminal act of stealing someone's car without their permission or will. The statistics show that a car is stolen in every 23 seconds average. Thieves takes less than a minute to successfully steal a car and are growing with developed technology. Many a times the alarms and sensors go unattended by the owners which acts as a huge advantage for the thieves. We observed that car theft is reported in two ways either through police reports or through the platform of social media.

The main purpose of our study is propose an idea to block the car in such a way if the car seems to be stolen then the owner will get sufficient time to reach the real time location of his/her car. The GPS tracking system, sensors, alarm systems does not completely prevent car theft but provides effective way to recover from it. It is observed through a survey that most people require a GPS tracking device which provides many features, like -Emergency feature, Accident coverage, Anti-Theft blockage, 24 hour history of routes, Real-time location, Report the police, Alerts Notification .Car theft can be recovered in an effective low cost technique if managed properly.

In this work different aspects of car theft are observed. Many techniques for car theft prevention like, RFID Technology, GPS tracking system etc are studied and analysed. From the analysis it is observed that the application should be developed in such a way that all the vehicle information should be visible to the owner such as fuel information, routes covered etc. The device must include systematic concept generation as well as many promising anti-theft definitions. It should work specifically in the fields of mobilization protection system, alarm system and sensors. Proper monitoring and reviewing should be done to get accurate feedbacks.

The structure of the work is as follows, in second section various techniques for car theft prevention are studied and analysed. A new method is proposed for car theft prevention in section 3. Section 3 also includes the survey of the various users regarding their requirements of the car theft prevention. The work is finally concluded in section 4 .

\section{RELATED STUDIES}

Car theft is a critical issue which needs to be handled carefully. Many car theft prevention techniques are given in literature like, GPS System, RFID technology, sensors. Figure (Fig. 2.1) shows the rate of car thefts of different states in India, the theft rates were calculated by National Crime Records Bureau it is shown as number of incidents per 100,000 of the total population .It is clear from the fig. that car theft is the critical issue and the work must be done for the prevention. In this section various case studies are discussed and analysed in terms of car theft prevention.

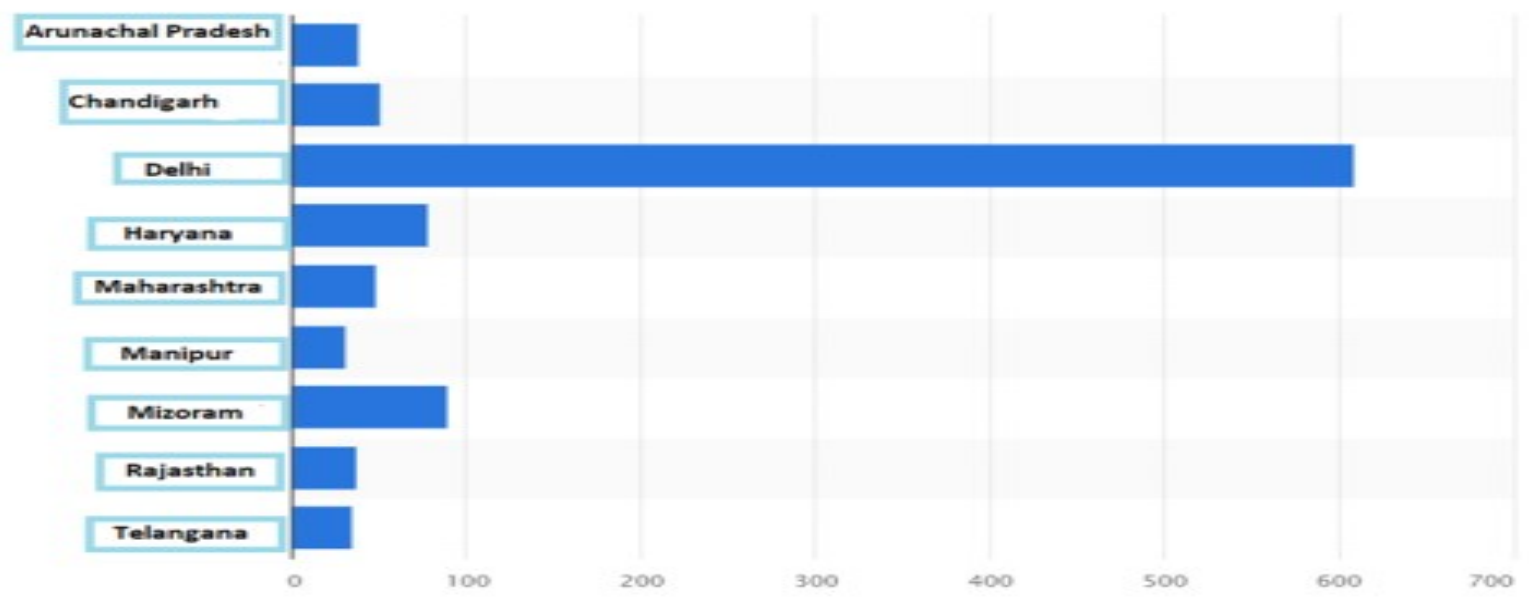

Fig. 2.1 Rate of Car Thefts of Different States in India

DOI Number: https://doi.org/10.30780/specialissue-ICACCG2020/022

Paper Id: IJTRS-ICACCG2020-022

pg. 108

(a)2017, IJTRS All Right Reserved, www.ijtrs.com 
ICACCG2020 30-31 July, 2020, Ansal University, Gurgaon, India

International Journal of Technical Research \& Science (Special Issue) ISSN No.:2454-2024 (online)

Here various case studies are considered and the features are analysed based on their usage.

\subsection{E-Z Rent A CAR}

E-Z Rent-a-car [7] is an independent firm for car rent in Florida which introduced the RFID technology to prevent their cars from stealing. The company wanted a secure system which automatically track vehicles, by doing streamlined operations and helps in employee accountability. Kevin Sas is the manager, he carried out a pilot program at Orlando International Airport to basically take effectiveness test of an RFID tracking system The company hired a security company: Global Access Control Systems to install the RFID system for tracking and managing E-Z's fleet of about 2,000 rental vehicles in Orlando. RFID Tags are almost the size of a mailing label, they are fixated to each vehicle's windshield. The tags have the capability to store data such as vehicle's model, colour, make, physical location and gas capacity [7]. These tags can be activated and deactivated through the use of a software system that costs about $\$ 10,000$ for installation per rental location. The RFID tags are connected via radio waves to electronic device on the rental lot that then reads the data that is stored in those tags. The employees of the company make use of the system software to authorize a tag to leave from the parking lot and automatically triggers the exit gate to open. By the use of this system it allows a customer to drive off without being scanned by a barcode scanner gun[7]. Figure (Fig. 2.2) shows the use of RFID tags on cars to identify, track and manage them.

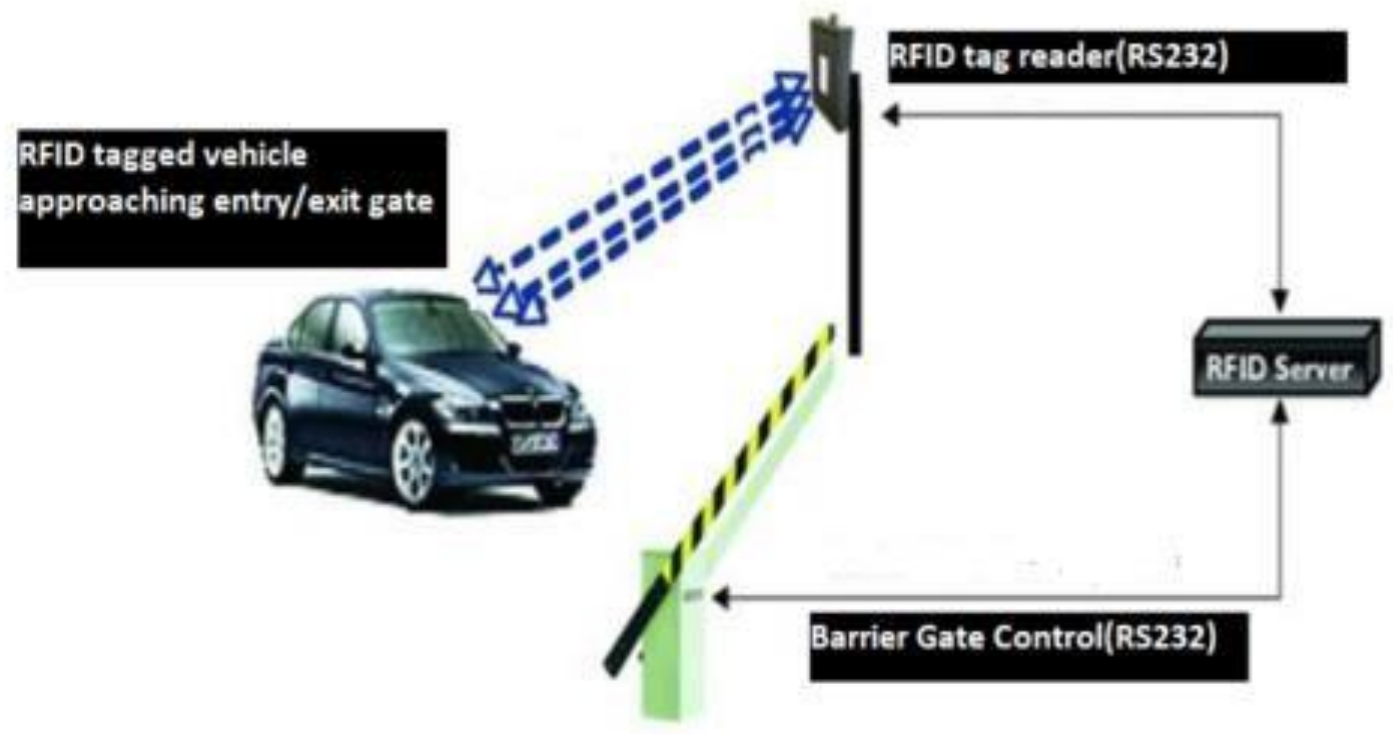

Fig. 2.2 Use of RFID Tags on Car

This is an easy, time-saving systematic way to keep track of all the vehicles, their location, total number of vehicles that are presently on rent and number of vehicles that are on ground. The system has reduced the company's overall security costs and human factor such as less guards.

\subsection{Avis on Location}

Avis budget group and I.D system developed a wireless car management system for corporate industry [7]. The method deals with virtual management of cars and their tracking. Over the time span of first five year, it costs around $\$ 14$ million. It enables the system to work on two major components that includes RFID (Radio Frequency Identification) and a smartphone. Clients can use avis on budget program to rent any car virtually through their smartphones at any location [7]. The method is in strong competition with companies like Zipcar by charging on hourly basis without staffing employees. This system can provide service quickly with few to as many as cars needed. The program allows one to communicate such that one can book flexibly from any location. The system generates transactions virtually once the payment and operation is completed. It collects all the car information such as fuel details, billing, information about odometer. The company believed that virtually renting car through smartphones will increase their business at a higher rate.

\subsection{TESLA Car Security}

Cars have advanced technology to prevent from theft according to the Silicon Valley automaker in both minimal thefts and recovery rate [11]. Tesla car security has 3 main features to prevent its theft that are sentry mode, GPS tracking system and pin to drive. 
ICACCG2020 30-31 July, 2020, Ansal University, Gurgaon, India

International Journal of Technical Research \& Science (Special Issue)

ISSN No.:2454-2024 (online)

Sentry mode is a method which is used to detect thieves before they even try to attempt to steal a car. This feature leaves the little in the monitoring state. the front camera ,2 side cameras and the sensors installed in the car will remain active even when the car is off .Tesla observes its surrounding, notifies the owner if it seems that any individual is too close to the vehicle in an unlikely event that a theft is in progress.

GPS Tracking System Has always been the first security step in Tesla's car security. [11] By the use of tesla's phone application the user can see real time data of their vehicle location. If a car is ever stolen then the owners can use that phone application to inform the police about their car location.

Pin to drive hey another security feature in which the user is required to enter a pin in order to drive the Tesla car. The location of the pin pad shifts after each start up so as to prevent reading of the fingerprint smudges. The only way by which the pin can be reset yes by entering owners Tesla account credentials.

By following these 3 features Tesla becomes one of the most secure company in the world as it makes use of three different methodologies i.e. the sentry mode, GPS tracking system and a pin to drive security feature.

\subsection{Let's Track}

Lets track is most well designed app in GPS and mobile tracking system by enabling app to app or app to web solution [12]. It is developed in the field to strengthen IOT. It provides solution to track vehicles in the most easiest way. Lets track is available for two wheelers as well as for four wheelers also. Lets track provides a great help to secure your car from car theft by a device named 'AIS 140'. This device is installed in the car to increase efficiency, safety and profitability. These GPS trackers are easy to use, reliable and provides fast service [12]. This provides many features to the customers like-

$>$ Provides Connectivity-In the most remote areas, Lets track gets you fully covered with frequency band of GSM 850/900/1800/19COMhz

$>$ Rescue Feature-Whenever there will be an emergency, this feature will allow you track GPS location and alert you through notification.

$>$ Track Routes- Allows you track vehicles Realtime location

Engine On/Off-Checks the status of the engine whether its on or off

$>$ Antitheft Alarm-Whenever the owner realizes that the car is stolen, this feature will allow you to switch the engine off [12].

$>$ Engine Cut-Engine-This is an important feature, Whenever the car is stolen the owner can take control over the engine any time.

\subsection{Futuristic Technology}

The most common method to track cars is by the use of location tracking such as GPS OR GMS systems based on satellites or stations present at ground .The tracking systems are integerated with some application program interface (API) to form a software application so that the customer i.e. the car owner can smoothly operate the application and easily track the car location and perform various other functions. Geofencing is another method by which it is seen that if the car has been moved or tilted from its parked location,then there is a possible chance of theft, therefore, in that case the fuel supply of the car will be made cut off slowly.A lot of antitheft devices are used such as locking devices like steering lock wheel ,car alarm system which merely stop the proffesional theives from stealing, they can easing cut off the wires of the antitheft systems installed in car.Therefore a simple yet strong, solid solution in form of a system is required which is also user-friendly to tackle this crime or example cut off of fuel supply, jamming the tires etc.

\section{PROPOSED METHOD}

Based on our research, a method is proposed in which the various technologies-RFID system, button sensor, noise sensor, light sensor, GPS tracking system are included to provide an effective system in a cost friendly manner. For the implementation of the method, the survey has been done with 59 users and the survey report is followed by the car theft prevention method.

\subsection{User's Survey}

A user survey was conducted, to know how people would react to situation such as car theft. This survey will gather information about the thought process of different kind of people, i.e. what would be their first response whenever they face such situations. There were a set of questions such as will it be easier for people to have an mobile application that makes their work easier to locate their stolen cars. The fact that nearby police should also be linked with the app so that they also receive the notification about the stolen car automatically was also discussed in survey. The survey also collected suggestions from people about the expectations they have from such an application which will provide them theft security, full control of their cars through mobile application and can monitor the route completely.

DOI Number: https://doi.org/10.30780/specialissue-ICACCG2020/022 
ICACCG2020 30-31 July, 2020, Ansal University, Gurgaon, India

International Journal of Technical Research \& Science (Special Issue) ISSN No.:2454-2024 (online)

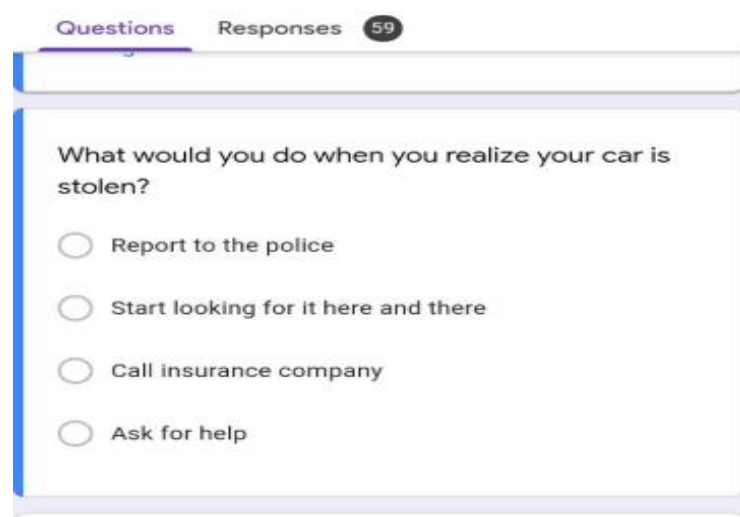

Would you like to have an app to track your car routes with all the history and alert you in case of emergency?

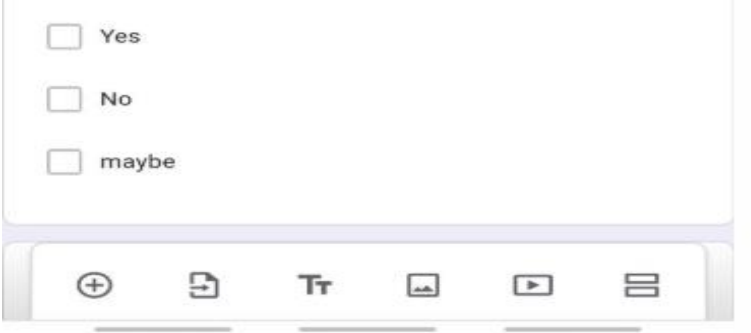

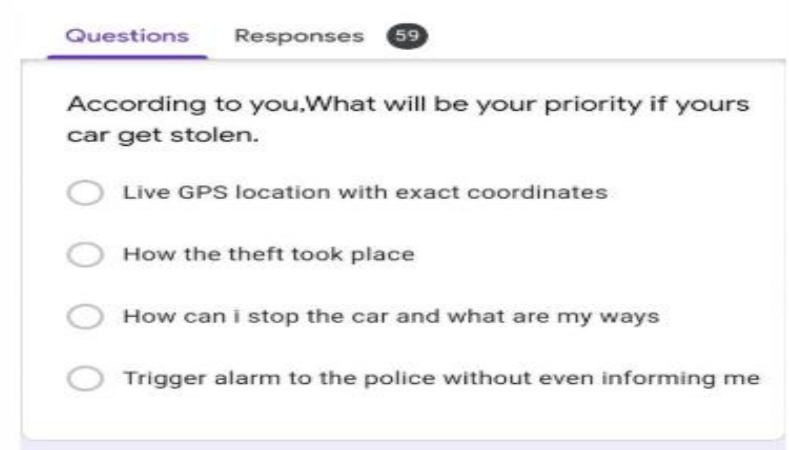

How can you prevent car theft before it happens.

Get a notification in your app to authenticate yourselv... Switch off the engine whenever someone tries to swit...

If you get the exact location of your stolen car,what do you expect.

Make the car tyres completely immobile

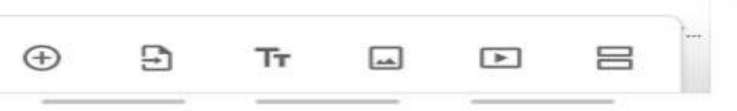

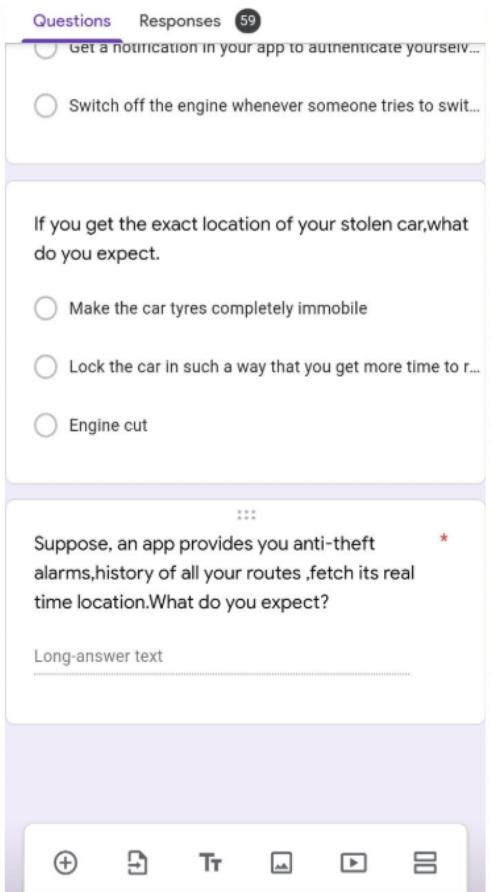

According to you, What will be your priority if yours car get stolen.

\section{9 responses}

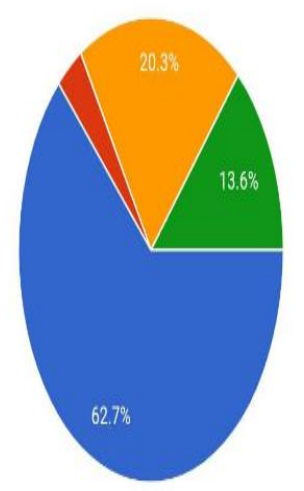
place
How can you prevent car theft before it happens.

59 responses

Live GPS Iocation with exact coordinates How the theft took

How can i stop the car and what are my ways

- Trigger alarm to the police without even informing me

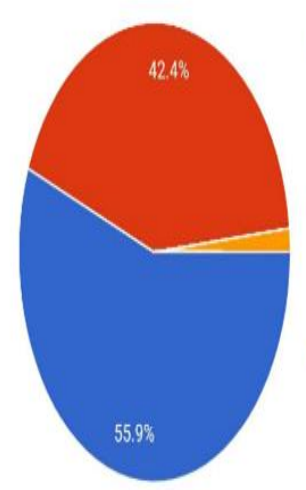

Get a notification in your app to authenticate yourselves whenever the car..

Switch off the engine whenever someone tries to switch it on - Get a notification in your app to authenticate yourselves when.

Fig. 3.1 The Survey Constituted of 59 Individuals with the Following Results

\subsection{Car Theft Prevention Method}

The mobile application will contain all the features mentioned in the previous section. The device will help to track the real time location of the car in case of any emergency, if the owner receives a notification from the app in case of a possible theft in progress then the application will contain a SOS feature in which the alarm will go off and a message will be sent to the nearest PCR police station and the owner will have a choice to lock the car in such the way that it will become immobile with a single tap from the application. The movement of car can be controlled by using EPB.

\subsubsection{EPB}

Electric parking brake is an advanced version of the conventional parking brake or the handbrake. EPB comes into use when a vehicle is parked or if the vehicle starts moving in the backward motion if on a slope. The EPB prevents 
ICACCG2020 30-31 July, 2020, Ansal University, Gurgaon, India

International Journal of Technical Research \& Science (Special Issue) ISSN No.:2454-2024 (online)

the movement of the vehicle i.e. the vehicle comes to a standstill in scenarios such as when parked or when on a ramp. Normally, EPB operate only to the rear wheels of a vehicle. The operational working of EPB is almost instantaneous and efficient. Therefore, improvises the reliability of car braking mainly because of the absence of some mechanical connected connections. The EPB has three main components: module of Electric Brake, motor electrically connected or Actuator and Cabin contains Electric switch.

The complete process of the proposed method is shown in Figure (fig. 3.2).

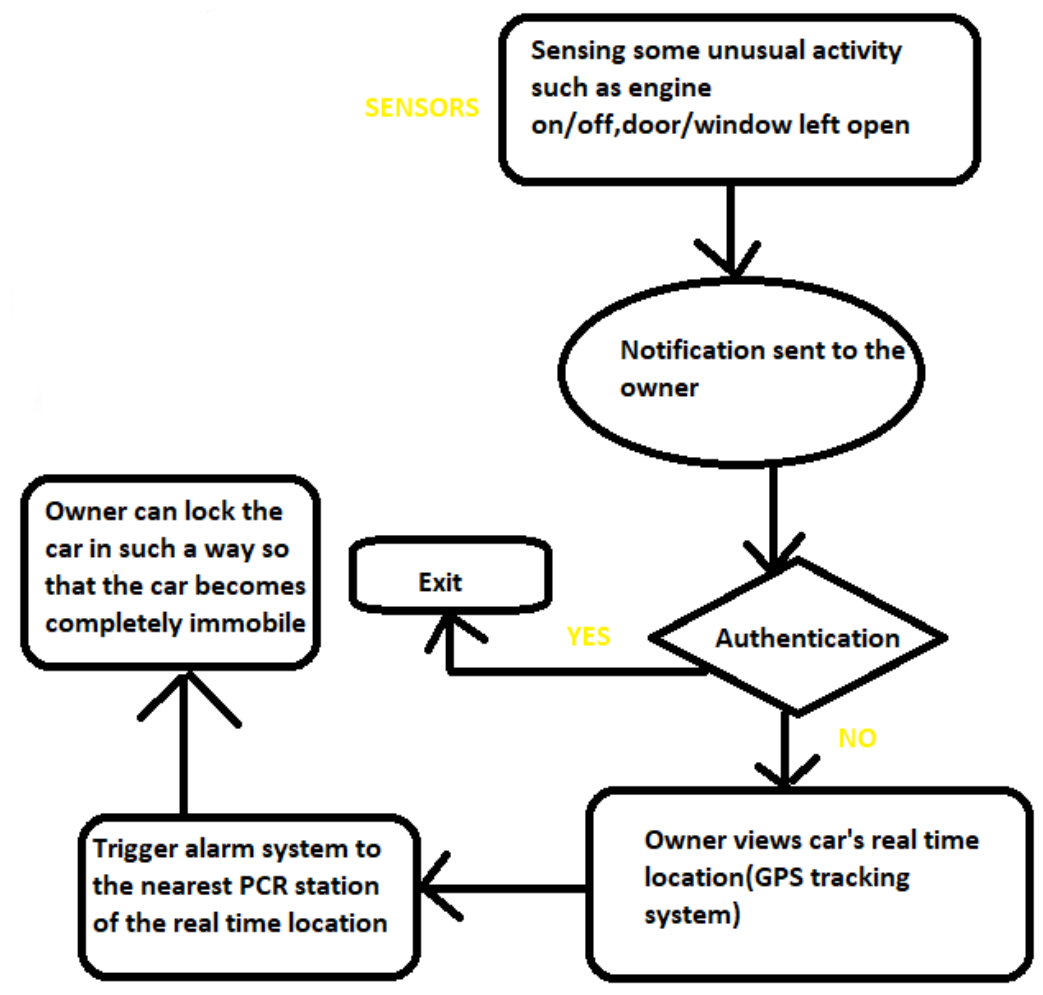

Fig. 3.2 The Working of the Proposal Car Theft Prevention Method

\subsection{Analysis of the Proposed Method}

The method proposed by us included all the technologies like GPS System, RFID technology, sensors and some other key values discussed below.

Features of the proposed method-

$>$ 1.This method helps to track the exact location of the cars with $x-y$ coordinates using a GPS system and RFID technology.

$>$ 2.This method can scare off the thief by installing the alarm system with noise, button and light sensors. The notification will be sent on the owner's mobile phone in case any one of the sensor also responds in favor of a supposed incident and the alarms (an alarming sound) will go active.

Hence the owner can take any further actions they want to. The aim is to create a cost effective kit for installation of all the devices and an application so that it is affordable to even a normal person.

\section{CONCLUSION}

In this paper different phenomenon of car thefts were studied, researched upon and then put together. An application is discovered based on the promising concepts. This paper also proposed an idea to manage and recover from car thefts in an effective manner. In recent years the crime rate is increasingly rapidly with the advancement in technology so to tackle these issues we need to think out of the box.

\section{REFERENCES}

[1] Deborah Lamm Weisel William R.Smith, G. David Garson ;Alexi Pavlichey, Julie WartellMotor, Vehicle Theft: Crime and Spatial Analysis in a Non-Urban Region,U.S Department of Justice

[2] D.Savitz,Automobile Theft Leonard,The Journal of Criminal Law and Criminology, Volume 50, Issue 2, 1950

[3] Beverly N. W. Lee and Giannina P. Rikoski, Vehicle Theft Prevention Strategies

[4] Nick Morgan, Oliver Shaw, Andy Feist and Christos Byron,Reducing criminal opportunity: vehicle security and vehicle crime

[5] https://www.autoslash.com/blog-andtips/posts/the-autoslash_guide_tocoping-with_a-stolen-rental_car

[6] Arthur O. Little, Vehicle Anti-Theft Security System Design, Volume II ,Technical Report, Inc., Cambridge, MA

DOI Number: https://doi.org/10.30780/specialissue-ICACCG2020/022

pg. 112 
ICACCG2020 30-31 July, 2020, Ansal University, Gurgaon, India

International Journal of Technical Research \& Science (Special Issue) ISSN No.:2454-2024 (online)

[7] https://www.autorentalnews.com/146632/tracking-your-vehicles_with_rfid

[8] DavidBarry,Jared, EugenePerchonok, WalterPreysnar,Harold,Preliminary study of the effectiveness of auto antitheft-devices.

[9] Juglar Diaz, Barbara poblete, Car Theft Reports: A Temporal Analysis from a social media perspectives.

[10] Somchoke, Juladis, Chaiwat Watcharajindasakul IoT solution for bad habit of car security.

[11] https://cleantechnica.com/2019/08/08/why_is-a_tesla_so_hard-tosteal/

[12] https://www.letstrack.in/tracking-devices/ais140_gps-trackergovernment_approved-gps-trackingdevice?pid=27

[13] Tarah Hodgkinson, Martin A. Angresen, Graham Farrell, The decline and locational shift of automotive theft: A local level analysis

[14] Patrick Curtin, David Thomas, Daniel Felker, Eric Weingart, Assessing Trends and Best Practices of Motor Vehi auto Theft Prevention Programs.

[15] Nick Morgan,Oliver Shaw, Andy Feist, Christos Byron, Reducing Criminal Opportunity: Vehicle Security and Vehicle crime.

[16] Chin-Ling Chen Mei-Li Chong A radio frequency identification application for car theft prevention in parking lot management systems

[17] Howe, Harlan, Jr., and Christine Blanchard., Wireless technology for automobile theft prevention, Microwave Journal, vol. 37, no. 1, Jan. 1994.

[18] Rohitaksha K , Madhu C G , Nalini B G ,Nirupama C V, Android Application for Vehicle Theft Prevention and Tracking System

[19] Graeme R. Newman,Car Safety and Car Security: An Historical Comparison, State University of New York at Alban

[20] James Byrne, Gary Marx, Technological Innovations in Crime Prevention and Policy.A Review of the Research on Implementation and Impact.

[21] R Bavya ; R Mohanamurali, Next generation auto theft prevention and tracking system for land vehicles

DOI Number: https://doi.org/10.30780/specialissue-ICACCG2020/022 